\title{
Leonardo Depicted America: Misread as the Moon
}

\author{
Stefaan Missinne ${ }^{1 *}$, Geert Verhoeven ${ }^{2}$ \\ ${ }^{1}$ Royal Geographical Society, London, UK \\ ${ }^{2}$ Ludwig Boltzmann Institute for Archaeological Prospection \& Virtual Archaeology, Vienna, Austria \\ Email: ^missinne@aon.at
}

How to cite this paper: Missinne, S., \& Verhoeven, G. (2019). Leonardo Depicted America: Misread as the Moon. Advances in Historical Studies, 8, 139-147. https://doi.org/10.4236/ahs.2019.84011

Received: July 16, 2019

Accepted: September 14, 2019

Published: September 17, 2019

Copyright (c) 2019 by author(s) and Scientific Research Publishing Inc. This work is licensed under the Creative Commons Attribution International License (CC BY 4.0).

http://creativecommons.org/licenses/by/4.0/

\begin{abstract}
Leonardo da Vinci must have been aware that Columbus discovered new territories in the West. Until now, no material evidence had been found to substantiate this assumption. Here we show that Leonardo not only read Amerigo Vespucci's letter (derived from a painted star constellation), but that he even drew a map including the New World, a drawing which was previously interpreted as a depiction of the Moon. Finally, Leonardo engraved his notion of this new continent on an ostrich egg globe (now known as the Da Vinci Globe) and made a copper cast of this. Both the cosmographic and cartographic clues demonstrate that Leonardo da Vinci knew about the fourth continent, to be named "America" in 1507, less than a decade after Columbus embarked upon its shores. This expansion of Leonardo's cartographic legacy comes at a time of increased interest for such multi-disciplinary insights, as the world commemorates in 2019 the $500^{\text {th }}$ anniversary of his death.
\end{abstract}

\section{Keywords}

America, Codex Arundel, Da Vinci Globe, Leonardo da Vinci, New World

\section{Introduction}

Leonardo da Vinci is considered the universal genius of the Italian Renaissance. Sharing his lifetime with the rulers of the Italian city-states and driven by an unlimited desire for knowledge, Leonardo must have been aware that Columbus had discovered a new continent. However, no direct or indirect evidence could ever substantiate this assumption (Almagià, 1953; Seybold, 2011). Here we provide data that support this hypothesis, demonstrating that Leonardo was aware of the continent from Amerigo Vespucci's historical letter. In addition, that he even drew (in 1503) a map of the coastline of "America" and engraved (in 1504) 
on two halves of an ostrich egg his notion of the New World, to be used for a copper cast now kept at the New York Public Library. Both the cosmographic and cartographic clues demonstrate for the first time that Leonardo da Vinci knew about the fourth continent, later to be named America, less than a decade after Columbus embarked on its shores. Moreover, he was also the very first to cartographically depict it on a globular projection.

\section{Vespucci-Related Clues}

\subsection{Salvator Mundi Meets Mundus Novus}

The first clue can be found in the oil painting Salvator Mundi. The "Saviour of the World" depicts Christ gesturing in blessing while holding a transparent crystal orb in his left hand (Figure $1(\mathrm{~A})$ ). Long thought to be lost, the painting was declared as an authentic Leonardo Da Vinci in 2011 by more than ten of the world's foremost Leonardo scholars (Esterow, 2011). Soon after, some experts disputed this attribution because the rendering of the orb is devoid of standard optical effects (Isaacson, 2017; Noest \& Kemp, 2011). Given Leonardo's passion for optics, portraying the sphere without an inverted and reduced mirror of Christ's arm and robe was considered strange. However, some fundamental pictorial aspects have been overlooked.

The orb was always thought to be made of rock crystal, justified by the little points of lights on its southern surface that could symbolise minute crystal cavities (Kemp, 2011). To the north and west of those, a right-angled triangle constellation

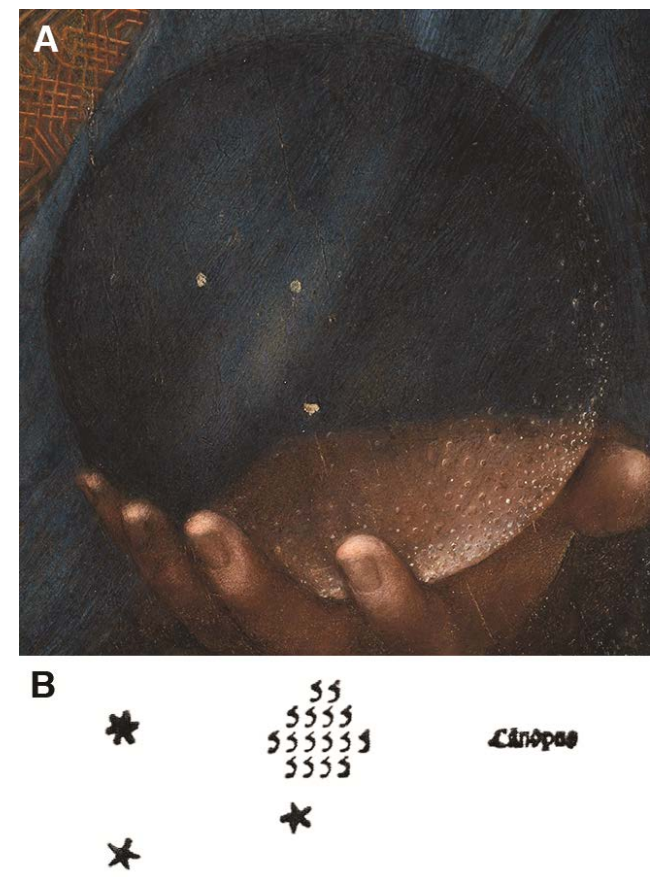

Figure 1. The bright stars of the Southern Cross, illustrated in a trigoni orthogoni schema on a transparent orb in Leonardo's Salvator Mundi painting (A) and printed in Amerigo Vespucci's letter about the Mundus Novus (B). (A) Public Domain; (B) from (Richter, 1883). 
of three bright points can be seen (Figure 1(A)). These spots were visible before the painting's restoration and were therefore not an induced artefact (Dianne Dwyer Modestini, pers. comm.), but nobody has ever paid attention to their distinctive triangular pattern. Apart from an unfounded interpretation as the brightest moons of Jupiter (Keim, 2018), these spots have been overlooked or merely judged as highlights (pers. comm. Martin Kemp). Upon mutually comparing this painting with a celestial depiction (Figure 1(B)) from Amerigo Vespucci's Mundus Novus ("New World" letter to Lorenzo di Pierfrancesco de' Medici), both the smaller and three larger dots of light are believed to represent stars in the Southern Celestial Hemisphere.

In his "New world letter" from 1502-3 (Omodeo, 2014), Vespucci describes his third voyage in 1501-1502 to the landmass that Columbus wrongly presented as the coastal lines of Asia. His text is considered the first written articulation of the idea that a fourth continent, an entirely "New World", was discovered. The Latin content describes that the southern celestial pole does not have an Ursa Major and Minor (Great and Lesser Bear), and no bright star can be discerned. Instead, the stars that are most apparent in the Southern Hemisphere form a right-angled triangle or "trigoni orthogoni schema" (Perini, 2013).

These three stars belong to the Southern Cross asterism, which is part of the Crux constellation. Known in antiquity, the stars gradually left the Northern hemisphere until they were rediscovered by $15^{\text {th }}$-century travellers who decided to use them for navigation. Since the drawings of these navigators never entered the public record, the letter by Vespucci is the first extant public account of the southern sky observations (Dekker, 1990). For this reason, these three bright spots on Christ's orb are considered stars. They are pictorial and cosmographic support for the initial hypothesis and therefore constitute the terminus post quem of the Salvator Mundi painting. The angle formed by the painted three stars seems to be larger than ninety degrees, but this rendering is entirely normal. It results from the perspective distortion characteristic for a two-dimensional painting when portraying a right-angled constellation that follows the three-dimensional curvature of the orb, a topic that Leonardo understood and mastered in this painting.

None of the later copies of this painting seem to portray a clear celestial sphere that includes these distinct New World-related observations. Analogous, all the smaller light spots at the bottom of the orb can be considered smaller stars, some of which are described by Vespucci like "unus canopus albus eximie magnitudinis", i.e. a group of extreme size (Perini, 2013). These findings substantiate why there are no optical distortions in the orb. It is merely a transparent sphere of the universe. It is Leonardo's depiction of the cosmos, a representation that does not follow the optical rules of reflection and refraction.

\subsection{Codex Arundel}

Besides this indirect contemporary connection with Amerigo Vespucci exemplified by Leonardo's painting, there is a written indication that Leonardo was in 


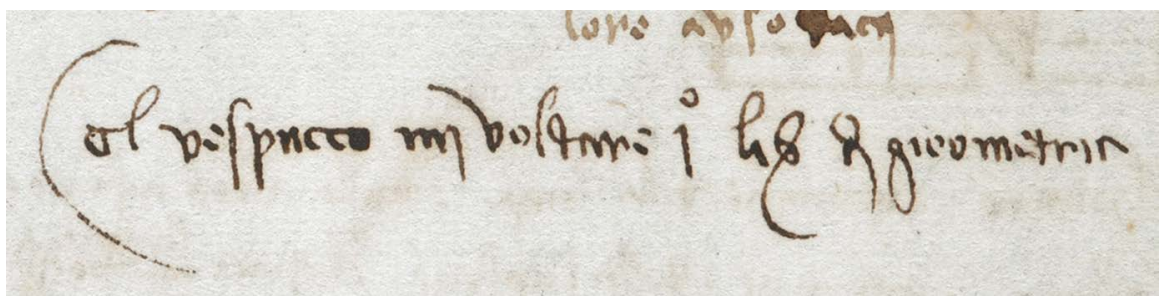

Figure 2. Leonardo's handwriting about Amerigo Vespucci (Codex Arundel page 132 verso; rotated $90^{\circ}$ clockwise and mirrored vertically). Copyright: The British Library Board, Codex Arundel Ms. 263.

contact with the man in whose honour the newly discovered continent was named in 1507. In the year 1503, Leonardo writes in his Codex Arundel page 132 verso: "El Vespuccio mi vol dare uno libro di gieometria" (Figure 2): "Thé Vespuccio wants to give me a book about geometry".

This brief phrase is remarkable for three reasons. First: It is known that Vespucci never returned to Florence after his discovery travels, so Leonardo could never have met him (Missinne, 2018). As such, they must have been in contact through third-parties. Second: the beginning of the sentence verbalises Leonardo's great respect for Vespucci ("El Vespuccio"). This means as much as "The great Vespucci" and supports the deposition that he does not refer to any other member of the Vespucci family. Third: Leonardo is once more displayed as a scholar with a keen interest in geometry, a branch of mathematics for which he was strongly influenced by his friend and mathematician Luca Pacioli (Pisano, 2016). Combined with his artistic skills and the notion of a fourth content, these geometric insights find their culmination in the creation of the oldest engraved globe depicting the Novus Mundus in 1504, based amongst others on a geographical sketch in one of his contemporary notebooks. The latter two cartographic clues further corroborate that Leonardo knew about the newly discovered continent.

\section{Pictorial Clues}

\subsection{Codex Arundel Again}

The sketch mentioned above is from the Codex Arundel. This in itself is not surprising. Quite a number of the geographical drawings in Leonardo's codices reveal that he played a crucial role in Renaissance cartography, for example through his bird's-eye view maps of the Tuscany valleys, but also those that cartographically depict (portions of) the world (e.g. Codex Atlanticus page 252 verso, page 283 recto and page 521 recto; Codex Forster II page 36 recto and page 41 recto, Codex Forster III page 31 verso; Codex Madrid I page 6 recto and page 64 recto; Paris Manuscripts Ms A page 56 recto and Ms I page 29 verso). However, two small illustrations on the lower right side of page 104 recto in $\mathrm{Co}$ dex Arundel Ms 263 (Figures 3(A)-(C)) appear to have passed unnoticed. Both portray the world globe using two different projections.

Upon rotating the page $90^{\circ}$ counter-clockwise, the first illustration (Figure 3(D)) 

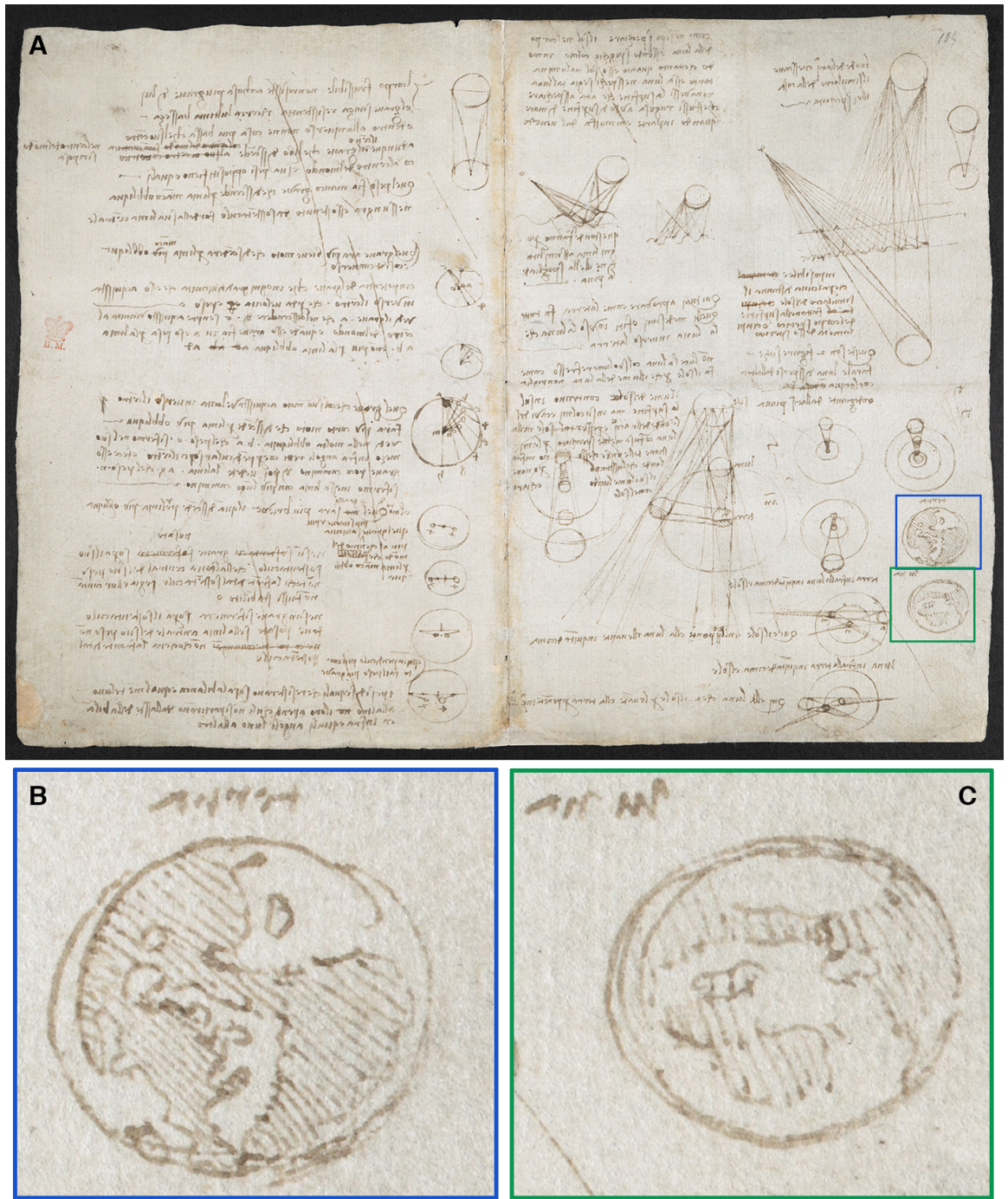

D

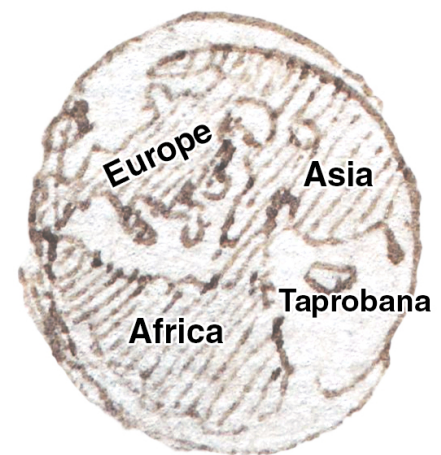

C

E

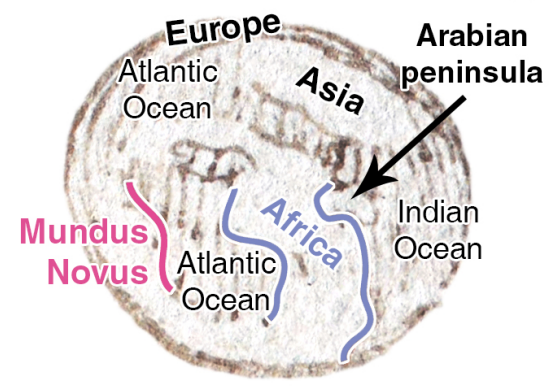

Figure 3. Page 104 recto of Leonardo's Codex Arundel Ms 263. (A) shows the complete page, (B) and (C) display the drawings indicated in (A). (D) and (E) represent the interpretations of (B), and (C), respectively. (A-C) Copyright: The British Library Board, Codex Arundel Ms. 263.

conveys the Ptolemaic World. The three known old continents of the world are represented hatched. Europe is depicted in the upper left, Northern Africa in the lower middle half and Asia in the upper right. In between, oceans and the Medi- 
terranean devoid of any hatching can be found. The open Indian Ocean is drawn in the lower right and surrounds the characteristic island of Taprobana (Sri Lanka). Since the word above this drawing has been deciphered as Terra or Earth (Richter, 1883), scholars have always considered this drawing to be a depiction of the Earth (Muratori \& Paganini, 2016). However, nobody seems to have ever correctly interpreted this illustration as a rotated version of the Ptolemaic World.

The second drawing is sketchier (Figure 3(C)). Richter neglected to decipher its one-word description, but the analogy with Leonardo's writing in the middle of the page confirms the word to be Luna or Moon. The combination of Luna and the specific location of the drawing-in a section illustrating the position of the Sun and the Moon (Figure 3(A)) - enticed Leonardo scholars to identify this sketch as the Moon (Muratori \& Paganini, 2016). Leonardo's drawings of the Moon (Codex Atlanticus Ms 263 page 310 recto) lack, however, any resemblance in style and content, thereby excluding this drawing to portray the Moon. This second sketch is another representation of the globe, now with the shoreline of the New World included (Figure 3(E)).

In contrast to his Ptolemaic world drawing, Leonardo hatches the water bodies and leaves the landmasses blank, thereby complicating the interpretation of this illustration. Nevertheless, taking into account the hatching, the sketchy nature of the drawing and the world view from early $16^{\text {th }}$ century Renaissance, one can discern the African continent in the middle with the hatched Atlantic Ocean to the right. The west coast of Africa is clearly illustrated as is the large protruding part on the eastern coast of Africa. The African east coast touches the Indian Ocean, substantiating that Leonardo had access to charts created after the circumvention of Cape of Good Hope. A uniquely slim longitudinal width characterises the central part of the African continent. Only the north of the African continent is displayed due to the tilted projection of the sketch. The Atlantic Ocean is portrayed in two separate parts, but Leonardo made corrections to its southern part, moving it further north. The Asian continent is rendered in the upper right of the drawing. Most remarkable is the distinctive coastal line of Brazil on the lower left side of the portrayal, represented with its noticeable curvature towards the south. Similar to the 1502 Cantino world map, the southern contour ends in the unknown. North and Central America are missing. Two small islands in the Caribbean, possibly Cuba and Santo Domingo, can barely be seen.

This drawing is the hitherto first known cartographic depiction of America by Leonardo. It illustrates how he was monitoring the latest geographical discoveries in his notebooks, while the inversed hatching and the caption Luna even seem to indicate deliberate enigmatic pictorial encryption. The creation of this illustration-dating from 1503-coincides with a period in Leonardo's life in which he researched Euclidian geometry and worked as a cartographer. In 1504, the combination of all his unique insights led to the creation of an ostrich egg 
globe, now known as the Da Vinci Globe and the oldest engraved globe to show the New World.

\subsection{Da Vinci Globe}

The critical evidence to support the initial hypothesis is provided by a recently-discovered early sixteenth-century globe engraved by a left-handed artist (Missinne, 2013). This small (ca $11 \mathrm{~cm}$ diameter) and lightweight (134 g) artefact is constructed from the lower halves of two different ostrich eggs which originate from Pavia. The globe has intricately braided waves engraved in anonymous seas and oceans reflecting the oceanic currents (Figure 4). These bear a faded dark blue/black colour, applied with iron gall ink, which does not rub off but impregnates the organic material of the surface engravings on the eggshell. This Da Vinci Globe is the model for its copper-casted identical twin, i.e. the Lenox Globe, stored at the New York Public Library. Prior to the discovery of this engraved egg globe, the Lenox Globe was considered the earliest post-Colombian globe in existence (Missinne, 2013).

Pictorial analysis of the Da Vinci Globe reveals that it mirrors Leonardo's earlier globe illustration from the Codex Arundel. It displays the three known Old World continents: the Ptolemaic-enlarged Asia, Europe and the in 1487 circumvented Africa. The latter uniquely features a narrow longitudinal width as in Leonardo's second globe drawing. The New World has the iconographic form of a cornucopia, most likely reflecting the richness of the "newly-born" continent. The unnamed island of Newfoundland is the only part of North America that appears on this globe. This is only five years after Gaspar Corte-Real made a

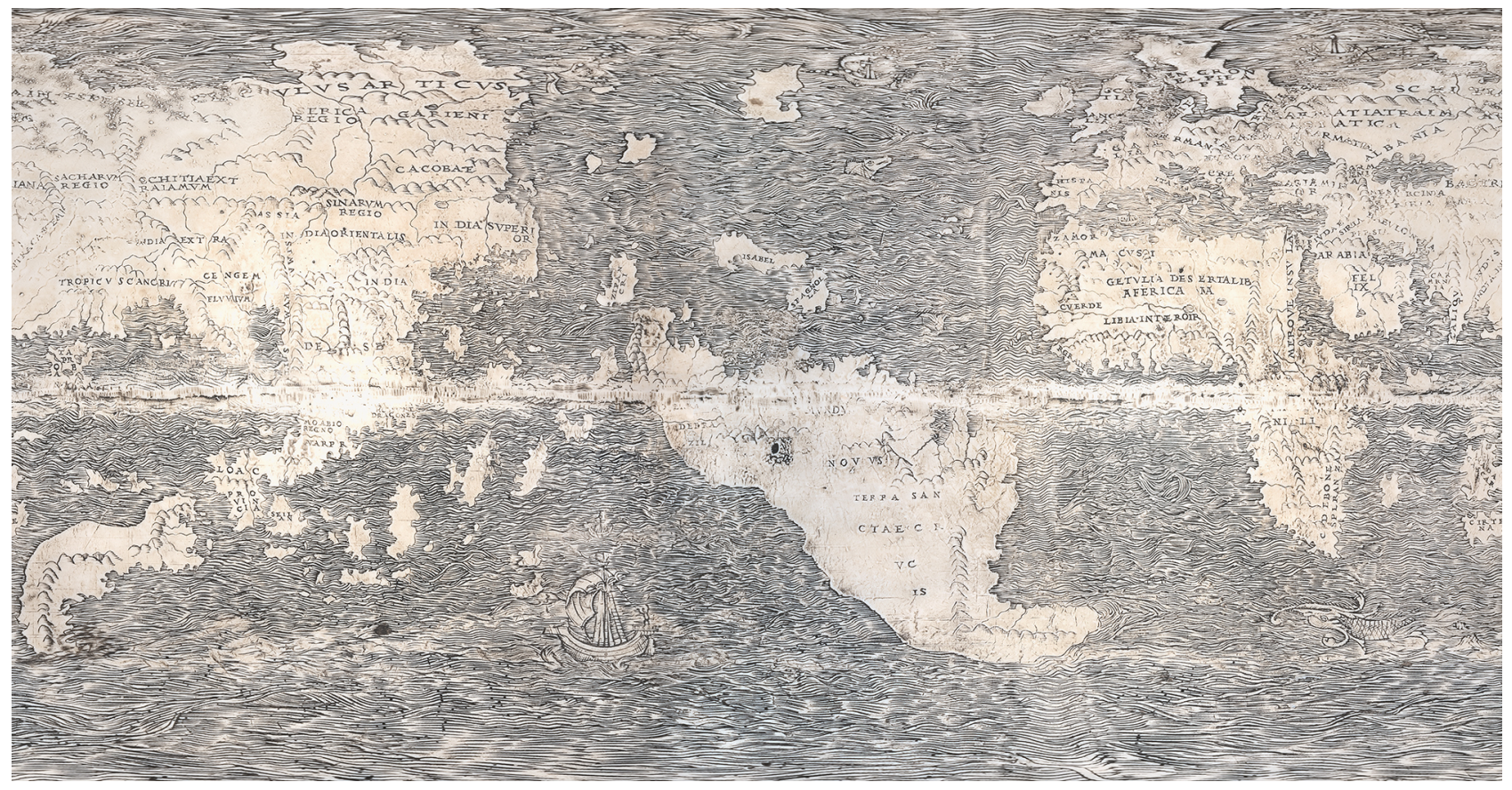

Figure 4. The Da Vinci Globe unfolded using an equirectangular map projection (Verhoeven \& Missinne, 2017). This map depicts the world according to Leonardo da Vinci while in Florence (Italy) in 1504. Copyright Stefaan Missinne 2018. 
landing on its shores in 1499. The open Western Sea passage, which is the most important seaway to the richness's of Asia and which was sought after as a short alternative for the lengthy circumvention of Africa, is delineated.

In addition to the analogies illuminated with this sketch, a multitude of interdisciplinary findings (chemical, iconographic, mathematical, cartographic and calligraphic) substantiate Leonardo da Vinci as the creator of this ostrich egg globe and the Lenox Globe as its cast (Missinne, 2018). While living in Florence (Italy) in 1504, Leonardo engraved the preselected ostrich eggshells to commemorate the birth of the fourth continent: "America". Mundus Novus is engraved on the South American continent, precisely like Amerigo Vespucci baptised it.

\section{Conclusion}

Three pieces of cosmographic and cartographic evidence support the hypothesis that Leonardo da Vinci not only knew, but was even affected by the newly discovered world less than a decade after Columbus embarked upon its shores. First, he decided to include the bright stars of the Southern Cross-mentioned in Amerigo Vespucci's "New world letter" from 1502-3-on a transparent orb in the Salvator Mundi painting. Second, Leonardo cartographically depicts for the first time the New World on a globular projection in his Codex Arundel. Third, this particular sketch must have functioned as a preparatory drawing for his 1504 egg-engraved terrestrial globe in which Leonardo eternalized his notion of the Mundus Novus.

This important expansion of Leonardo's cartographic legacy comes at a time of increased interest for such multi-disciplinary insights. In 2019, the world commemorates the $500^{\text {th }}$ anniversary of Leonardo da Vinci's death and the $50^{\text {th }}$ anniversary of the Apollo 11 Moon landing. For many centuries, it was exactly that astronomical body scholars erroneously believed Leonardo portrayed in his Codex Arundel.

\section{Author's Contributions}

Conceptualisation, S.M. and G.V; Methodology, S.M.; Investigation, S.M. and G.V.; Resources, S.M.; Writing-Original Draft, S.M.; Writing-Review \& Editing, G.V and S.M.; Visualization: G.V.

\section{Conflicts of Interest}

The authors declare no conflicts of interest regarding the publication of this paper.

\section{References}

Almagià, R. (1953). Leonardo da Vinci geografo e cartografo. In Firenze-Pisa-Siena, Italy, 15-18 gennaio 1953 (pp. 451-466). Firenze: Olschki.

Dekker, E. (1990). The Light and the Dark: A Reassessment of the Discovery of the Coalsack Nebula, the Magellanic Clouds and the Southern Cross. Annals of Science, 47, 
529-560. https://doi.org/10.1080/00033799000200391

Esterow, M. (2011). Rediscovering a Leonardo. How Experts around the World Concluded that "Salvator Mundi" Was a Lost Work by the Master (pp. 100-105). ARTnews.

Isaacson, W. (2017). Leonardo da Vinci. New York: Simon \& Schuster.

Keim, F. (2018). Salvator Mundi. Die Entdeckung der JUPITERMONDE durch durch Leonardo, Dürer und Giorgione. Ulm, Germany: Universität Ulm.

Kemp, M. (2011). Art History: Sight and Salvation. Nature, 479, 174-175. https://doi.org/10.1038/479174a

Missinne, S. (2013). A Newly Discovered Early Sixteenth-Century Globe Engraved on an Ostrich Egg: The Earliest Surviving Globe Showing the New World. The Portolan, 87, 8-24.

Missinne, S. (2018). The Da Vinci Globe. Newcastle upon Tyne: Cambridge Scholars Publishing.

Muratori, C., \& Paganini, G. (2016). Early Modern Philosophers and the Renaissance Legacy. In International Archives of the History of Ideas (Vol. 220). Cham: Springer International Publishing.

Noest, A. J., \& Kemp, M. (2011). No Refraction in Leonardo's Orb. Nature, 480, 457. https://doi.org/10.1038/480457a

Omodeo, P. T. (2014). The Authenticity of Amerigo Vespucci's Mundus Novus and Information Untold about His Third Journey. Nuncius, 29, 359-388. https://doi.org/10.1163/18253911-02902001

Perini, L. (2013). Vespucci, Amerigo. Cronache epistolari: Lettere, 1476-1508. Firenze: Firenze University Press.

Pisano, R. (2016). Details on the Mathematical Interplay between Leonardo da Vinci and Luca Pacioli. BSHM Bulletin: Journal of the British Society for the History of Mathematics, 31, 104-111. https://doi.org/10.1080/17498430.2015.1091969

Richter, J. P. (1883). The Literary Works of Leonardo Da Vinci: Compiled and Edited from the Original Manuscripts (2nd ed.). London: Sampson Low, Marston, Searle \& Rivington.

Seybold, D. (2011). Leonardo da Vinci im Orient: Geschichte eines europäischen Mythos. In Studien zur Kunst (Vol. 18). Köln: Böhlau Verlag. https://doi.org/10.7788/boehlau.9783412213510

Verhoeven, G. J. J., \& Missinne, S. J. (2017). Unfolding Leonardo da Vinci's globe (AD 1504) to Reveal Its Historical World Map. ISPRS Annals of Photogrammetry, Remote Sensing and Spatial Information Sciences, $I V-2 / W 2$, 303-310.

https://doi.org/10.5194/isprs-annals-IV-2-W2-303-2017 